\title{
KEBIJAKAN FINANCING TO VALUE, FINANCING TO DEPOSIT RATIO DAN PENGARUHNYA TERHADAP PEMBIAYAAN RUMAH DI JAWA TIMUR TAHUN 2013-20151
}

Muhammad Rachmad Hidayat

Mahasiswa Program Studi S1 Ekonomi Islam Fakultas Ekonomi dan Bisnis Universitas Airlangga

Email : rachmad-12@feb.unair.ac.id

Sri Herianingrum

Departemen Ekonomi Syariah Fakultas Ekonomi dan Bisnis Universitas Airlangga

Email : Sri.herianingrum@feb.unair.ac.id

ABSTRACT

The purpose of this research is to analyze the impact of the macroprudential policy that applied in Indonesia (in this case are Financing to Valve and Financing to Deposit Ratio) on house financing in East Java.

The object of this research are financing to value and financing to deposit ratio, and the subject of this research is house financing in 2013 until 2015. The data of this research are available in the website of the Bank Indonesia. Analysis method that used for this research is the multiple linear regression with 0,05 signification

The result of this research shows if FDR, FTV aqd MMQ-IMBT are affecting partially positive significant to House Financing in East Java. Whilst FTV aqd Murabaha and Istishna' is affecting partially negative significant to house financing in East Java. Simultaneously, FDR, FTV aqd MMQIMBT and FTV aqd Murabahah and Istishna' giving significant impact to house financing in East Java

\section{Pendahuluan}

Krisis ekonomi dan keuangan yang terjadi di berbagai negara mulai dari negara berkembang hingga negara maju dapat menimbulkan gangguan pada stabilitas keuangan dan juga stabilitas keuangan dan juga stabilitas pembayaran. Bagi pembuat kebijakan seperti Bank Indonesia, krisis ekonomi dan keuangan merupakan suatu pelajaran untuk memperbaiki sistem moneter yang sudah ada sebelumnya. (Agung, 2010)

Kebijakan moneter yang berorientasi pada inflasi yang rendah seperti Inflation Targeting Framework (ITF) tidaklah cukup untuk mengatasi krisis ekonomi dan kevangan, maka perlu adanya sebuah instrumen regulasi prudensial di sektor perbankan yang diatur untuk menjaga stabilitas makroekonomi secara keseluruhan.

Krisis yang terjadi di Amerika Serikat pada 2008 yang kemudian menular ke berbagai negara di dunia menunjukkan bahwa ketidakstabilan di sektor keuangan berdampak serius pada sektor riil (Agung,2010). Krisis keuangan yang didorong oleh penggelembungan kredit berubah menjadi krisis global dan telah menyebabkan aktivitas perekonomian turun derastis. Classens et al., (2012) dan Hahm et al., (2011) berargumen bahwa 3 pelajaran penting dari krisis finansial. Pertama, dampak dari perkembangan di sektor keuangan ke sektor riil lebih besar 
Hidayat, et al/Jurnal Ekonomi Syariah Teori dan Terapan Vol. 5 No. 4 April 2018: 279-289; KEBIJAKAN FINANCING TO VALUE, FINANCING TO DEPOSIT RATIO DAN PENGARUHNYA TERHADAP PEMBIAYAAN RUMAH DI JAWA TIMUR TAHUN 2013-2015

dibandingkan perkiraan semula. Kedua, biaya dari penyelamatan krisis sangat besar.Ketiga, stabilitas harga dan output ternyata tidak menjamin kestabilan finansial. (Tim Riset SMF, 2015)

Sejalan dengan hal tersebut, perkembangan produk keuangan yang semakin canggih, perilaku ambil risiko sebagai akibat dari motif cari untung yang sebesar-besarnya dalam waktu yang sesingkat-singkatnya dan sistem keuangan global yang semakin terintegrasi menyebabkan perlunya tambahan kerangka berfikir yang bersifat makro namun terfokus pada sistem keuangan secara keseluruhan. Oleh karena itu, disusun suatu kerangka kebijakan guna menanggulani ketidak stabilan sistem kevangan, yaitu kebijakan Makroprudensial.(Mariza, 2015)

Menurut Bank of England (2009) kebijakan makroprudensial adala kebijakan yang ditujukan untuk memelihara kestabilan intermediasi keuangan (misalnya jasa-jasa pembayaran, intermediasi kredit, dan penjaminan atas risikol terhadap perekonomian.Sedngkan menurut International Monetary Fund (IMF) (2011), kebijakan makroprudensial adalah kebijakan yang memiliki tujuan utama yaitu untuk memelihara stabilitas sistem kevangan secara keseluruhan melalui pembatasan peningkatan risiko sistemik.

Penggunaan instrumen makroprudensial sebenarnya bukan hal yang baru. Hanya saja, instrument tersebut mengalami lebih bnayak penesuaian pasca krisis global tahun 2008. Negara-negara sedang berkembang (emerging market) mengguakan instrumen makroprudensial lebih luas dibandingkan negara-negara maju (antipa et et al., 2011; Galati dan Rchhid,2011, dan Tovar et al., 2012).

Beberapa negara menggunakan instrumen yang bervariasi. Penggunaan Instrumen tersebut tergantung pada tingkat perkembangan ekonomi dan keuangan, rezim nilai tukar dan daya tahan terhadap guncangan keuangan (Unsal, 2011). Indonesia merupakan salah satu negara emerging market yang sector keuangannya didominasi oleh industri perbankan, sehingga bila terjadi guncangan pada perbankan maka akan berdampak pada sektor keuangan secara keseluruhan.

Maka dari itu di Indonesia ditetapkan instrumen mitigasiresiko dengan komponen pembatasan Loan to Value (LTV) untuk perbankan konvensial dan Financing to Value (FTV), untuk perbankan syariah, untuk kredit pemilikan rumah (KPR) dan Kredit Kendaraan Bermotor (KKB) sebagaimana telah dimuat dalam Surat Edaran Bl No. 14/10/DPNP tanggal 15 maret 2012 untuk bank umum konvensial dan Surat Edaran No. 14/10/DPbS tanggal 27 November 2012 untuk bank umum syariah dimana ditetapkannya ratio LTV untuk bank yang memberikan KPR paling tinggi sebesar $70 \%$ untuk tipe bangunan diatas $70 \mathrm{~m}^{2}$ (tujuh 
Hidayat, et al/Jurnal Ekonomi Syariah Teori dan Terapan Vol. 5 No. 4 April 2018: 279-289; KEBIJAKAN FINANCING TO VALUE, FINANCING TO DEPOSIT RATIO DAN PENGARUHNYA TERHADAP PEMBIAYAAN RUMAH DI JAWA TIMUR TAHUN 2013-2015

puluh meter persegi). Surat edaran ini dikalibrasi ulang dengan Surat Edaran BI No. 15/40/DKMP pada tanggal 24 semptember 2013, dan yang terbaru adalah Surab Edaran BI No. 17/10.PBI/2015 tanggal 18 Juni 2015.

Kebijakan LTV dan FTV bertujuan untuk meredam risiko sistemik yang mungkin timbul akibat pertumbuhan KPR yang pada saat itu mencapai lebih dari $40 \%$ serta tingkat kegagalan nasabah KKB untuk memenuhi kewajiban yang pada saat itu mencapai hampir 10\%. Pertumbuhan KPR yang terlalu tinggi dapat mendorong peningkatan harga aset properti yang tdak mencerminkan harga sebenarnya (bubble), sehingga menyebabkan harga properti jatuh dan secara menyeluruh data menyebabkan perekonomian menurun sehingga terjadi resesi ekonomi. (Purnawarman,2015)

Indikator perbankan umum di Provinsi Jawa Timur juga memiliki pengaruh terhadap nilai jumlah penyaluran KPR di provinsi Jawa Timur.Loan to Deposit Ratio (LDR) dalam perbankan konvensional Financing to Deposit Ratio (FDR) dalam perbankan Syariah adalah salah satu indikator perbankan yang menjelaskan mengenai rasio antara besarnya seluruh volume kredit yang disalurkan oleh bank dan jumlah penerimaan dana dari beberapa sumber.

Rasio ini digunakan untuk menyatakan seberapa jauh kemampuan bank dalam membayar kembali penarikan dana yang dilakukan deposan dengan mengandalkan kredit yang diberikan sebagai sumber likuiditas bank, semakin likuid suatu bank maka akan mengakibatkan kenaikan volume kredit bank yang disalurkan. Menurut Bank Indonesia nilai LDR dan FDR yang paling sehat adalah $94,75 \%$ sehingga dana terhimpun dapat disalurkan dalam bentuk kredit yang merupakan asset yang paling produktif bagi bank, termasuk penyaluran kredit di sector khusus seperti KPR. (Suryani, 2011)

\section{Landasan Teori}

Tujuan Bank Indonesia seperti tertuang dalam undang-undang RI nomor 23 tahun 1999 Bab III pasal 7 adalah untuk mencapai dan memelihara kestabilan rupiah. Adapun kestabilan rupiah yang diinginkan oleh Bank Indonesia adalah :

a. Kestabilan nilai rupiah terhadap barang dan jasa

b. Kestabilan nilai rupiah terhadap mata vang negara lain

Dengan stabilnya nilai mata vang rupiah, maka akan mendukung pembangunan ekonomi yang berkelanjutan dan meningkatkan kesejahteraan rakyat. Agar kestabilan nilai rupiah dapat tercapai dan terpelihara, maka Bank Indonesia memiliki tugas antara lain (kasmir,2003) 
Hidayat, et al/Jurnal Ekonomi Syariah Teori dan Terapan Vol. 5 No. 4 April 2018: 279-289; KEBIJAKAN FINANCING TO VALUE, FINANCING TO DEPOSIT RATIO DAN PENGARUHNYA TERHADAP PEMBIAYAAN RUMAH DI JAWA TIMUR TAHUN 2013-2015

1. Menetapkan dan melaksanakan kebijakan moneter

2. Mengatur dan menjaga kelancaran sistem pembayaran

3. Mengatur dan mengawasi bank

\section{Kebijakan Makroprudensial}

Kebijakan makroprudensial adalah instrument regulasi prudensial yang ditujukan untuk mendorong stabilitas sistem keuangan secara keseluruhan, bukan keehatan lembaga keuangan secara individu. Tujuan kebijakan moneter adalah menstabilkan harga barang dan jasa dalam perekonomian. Sementara itu, tujuan dari kebijakan makroprudensial adalah untuk menjamin daya tahan sistem kevangan secara keseluruhan dalam menjaga suplai jasa intermediasi keuangan kepada perekonomian secara keseluruhan (Quint dan Pau, 2011: 11 dan Milne 2009: 19)

Kebijakan Makroprudensial jika dipandang secara umum dapat diartikan diartikan sebagai salah satu cara pemerintah melindungi perekonomian Negara agar tidak terjadi krisis ekonomi yang nantinya dapat merugikan masyarakat. Pemerintah memang diharuskan melindungi rakyatnya agar masyarakat tidak terkena imbas buruk dari kebijakan-kebijakan moneter yang terkadang membuat perekonomian di setiap Negara mengalami kenaikan dan penurunan, yang mengakibatkan naiknya harga-harga dari kebutuhan primer, salah satunya adalah rumah, sehingga haruslah pemerintah membuat kebijakan yang dapat membantu masyarakat agar tidak merasa terbebani akan harga rumah yang tiap tahunnya makin tinggi.

Menurut QS. Al-Anbiya ayat 73 :

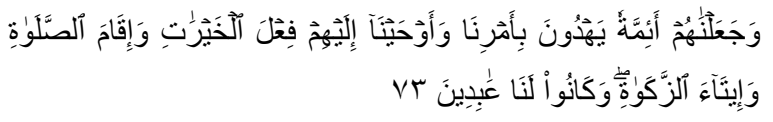
Wa Ja`alnāhum 'A'immatan Yahdūna Bi'amrinā Wa 'Awĥaynā 'llayhim Fi'la AlKhayrāti Wa 'lqāma Aş-Şalāati Wa 'İtā'aAzZakāati Wa Kānū Lanā 'Ābidīna

Artinya : "Kami telah menjadikan mereka itu sebagai pemimpin-pemimpin yang member petunjuk dengan perintah Kami dan telah Kami wahyukan kepada mereka mengerjakan kebajikan, mendirikan sembhayang, menunaikan zakat dan hanya kepada Kamilah mereka selalu menyembah."

(Departemen Agama RI, 2008:496)

Dari ayat diatas dapat juga diartikan jika para pemimpin diharuskan mengabdi kepada Negara dengan cara melindungi masyarakat, memiliki iman yang kuat agar tidak melakukan ke-dzaliman, dan haruslah memgatur pendistribusian harta orang yang berlebih kepada orang yang kekurangan harta.

Rasio Financing to Valve (FTV) adalah nilai rasio antara nilai kredit yang dapat diberikan oleh bank terhadap nilai anggunan pada saat awal pemberian suatu kredit (Surat Edaran Bank Indonesia no 14/10/DPNP).Kebijakan ini merupakan kebijakan yang dikeluarkan oleh Bank 
Hidayat, et al/Jurnal Ekonomi Syariah Teori dan Terapan Vol. 5 No. 4 April 2018: 279-289; KEBIJAKAN FINANCING TO VALUE, FINANCING TO DEPOSIT RATIO DAN PENGARUHNYA TERHADAP PEMBIAYAAN RUMAH DI JAWA TIMUR TAHUN 2013-2015

Indonesia sebagai bank sentral untuk mengantisipasi atau meminimalisir adanya gejolak dalam perekonomian sebagai akibat dari pertumbuhan kredit pemilikan rumah (KPR) dan kepemilikan atas kendaraan bermotor (KKB) yang terlalu tinggi.Sehingga Bank Indonesia selaku penguasa moneter di Indonesia merasa perlu untuk memberikan batasan-batasan yang jelas terhadap jumlah vang mukayang harus dimiliki seseorang jika ingin memiliki suatu perumahan ataupun kendaraan bermotor. (Purnawan, 2015)

\section{Financing to Value}

Konsep Loan to Value dan Financing to Value sebenarnya sama dengan Down payment, hanya saja istilah Loan to Valve dan Financing to Value lebih condong digunakan pada properti KPR, sedangkan down payment pada kendaraan bermotor. Terkhusus untuk Loan to Value dan Financing to Valve, tidak semua KPR yang akan dikenakan kebijakan berikut. Menurut Surat Edaran Bank Indonesia No. 14/10/DPNP ruang lingkup KPR yang diatur dalam surat edaran tersebut mencakup kredit konsumsi pemilikan rumah tinggal, termasuk apartemen namun tidak termasuk rumah toko dan rumah kantor, dengan tipe lebih dari $70 \mathrm{~m}^{2}$. Adapun dalam surat edaran ini juga telah ditetapkan rasio Loan to Value (LTV) dan Financing to Value (FTV) sebesar 70\%. Itu berarti bila sseorang ingin menikmati suatu fasilitas KPR harus memiliki vang muka setidaknya $30 \%$ dari harga jual KPR tersebut. (Purnawan, 2015)

\section{Financing to Deposit Ratio}

Financing to Deposit Ratio adalah rasio yang mengukur antara jumlah pembiayaan yang diberikan oleh bank dibagi dengan jumlah dana yang diterima oleh bank dalam hal ini dana pihak ketiga. (Hasan, 2015:4). Menurut Dendawijaya (2005:116), Financing to Deposit Ratio adalah kemampuan Bank dalam membayar kembali penarikan dana yang dilakukan oleh deposan dengan mengandalkan kredit yang diberikan sebagai sumber likuiditasnya. Perhitungan Financing to Deposit Ratio adalah sebagai berikut:

$$
\text { FDR }=\frac{\text { Jumlah total pembiayaan }}{\text { Total Dana Pihak Ketiga }} \times 100 \%
$$

Keterangan:

FDR : Financing to

Deposit Ratio

Jumlah Total Pembiayaan : Total pembiayaan yang diberikan kepada pihak ketiga (tidak termasuk pembiayaan kepada bank lain)

Total dana Pihak Ketiga : Dana pihak ketiga mencakup giro, tabungan dan deposito (tidak termasuk antara bank)

\section{Metodologi Penelitian}

\section{Pendekatan Penelitian}

Pendekatan penelitian ini menggunakan pendekatan kuantitatif karena data akan diambil dalam bentuk angka dan diproses secara 
Hidayat, et al/Jurnal Ekonomi Syariah Teori dan Terapan Vol. 5 No. 4 April 2018: 279-289; KEBIJAKAN FINANCING TO VALUE, FINANCING TO DEPOSIT RATIO DAN PENGARUHNYA TERHADAP PEMBIAYAAN RUMAH DI JAWA TIMUR TAHUN 2013-2015

statistik.Pendekatan kuantitatif dilakukan

dengan metode regresi Ordinary Least

Square (OLS). Teknik regresi dalam penelitian ini dikerjakan dengan SPSS 18.0

\section{Identifikasi Variabel}

Berdasarkan rumusan masalah dan model analisis, maka variabel - variabel yang digunakan dalam penelitian ini terdiri dari 2 jenis variabel yaitu variabel endogen dan eksogen

\section{Variabel Eksogen}

Variabel eksogen menurut Anshori (2009:57) disebut juga dengan variabel bebas atau independen merupakan sebuah variabel bebas yang menjadi pusat dalam penelitian, yang variabilitasnya atau keragamannya merupakan suatu kondisi yang ingin diteliti dan dapat mempengaruhi vriabel endogen

Variabel eksogen yang digunakan dalam penelitian ini adalah :

Financing to Value

\section{$\left(X_{1}\right)$}

Financing to Deposit Ratio

\section{$\left(X_{2}\right)$}

\section{Variabel Endogen}

Variabel endogen menurut Anshori (2009:57) disebut juga dengan variabel terikat atau variabel dependen merupakan variabel terikat yang menjadi akibat dari suatu masalah atau dipengaruhi karena variabel eksogen. Variabel endogen dalam penelitian ini, yaitu :

Pertumbuhan Pembiayaan Rumah

( $\mathrm{Y})$

\section{Jenis dan Sumber Data}

Jenis data yang digunakan dalam penelitian ini adalah data sekunder.Data sekunder menurut Adi (2015:12) adalah penggunaan data yang dikutip oleh si peneliti dari sebuah literatur. Data dalam penelitian ini diperoleh dengan mengakses dari www.BI.go.id. Dalam penelitian ini data sekunder yang digunakan adalah data bulanan FDR dan tingkat pertumbuhan pembiayaan rumah yang dilakukan perbankan umum syariah menggunakan data bulanan.Data diperoleh dari website Bank Indonesia dalam jurnal kajian ekonomi regional Jawa Timur periode 2012-2015. Sementara untuk data FTV digunakan sebagai variabel dummy untuk membedakan kebijakan FTV pada tahun 2012 dan 2015

\section{Prosedur Pengumpulan Data}

\section{Populasi dan Sampel}

Populasi menurut Sugiono (2014:80) adalah peneliti menarik suatu kesimpulan yang terdiri dari beberapa suatu obyek atau subyek yang memiliki suatukualitas dan karakteristik tertentu untuk dipelajari 
Hidayat, et al/Jurnal Ekonomi Syariah Teori dan Terapan Vol. 5 No. 4 April 2018: 279-289; KEBIJAKAN FINANCING TO VALUE, FINANCING TO DEPOSIT RATIO DAN PENGARUHNYA TERHADAP PEMBIAYAAN RUMAH DI JAWA TIMUR TAHUN 2013-2015

oleh si peneliti. Populasi dalam penelitian ini adalah Seluruh data FTV, FDR dan data penyaluran pembiayaan rumah yang dilakukan oleh perbankan umum syariah

Sampel menurut Sugiono (2014:81) adalah dari seluruh populasi yang memiliki beberapa karakteristik tertentu diambil dari sebagian dari jumlah populasi tersebut. Sampel ditetapkan menggunakan purposive sampling, dengan kriteria sebagai berikut :

1. Data rasio FTV yang telah ditetapkan oleh Bank Indonesia pada tahun 2013-2015 (data bulanan)

2. Data FDR hitung seluruh perbankan umum syariah pada tahun 2013-2015 (data bulanan)

3. Data penyaluran KPRiB pada tahun 2013-2015 (data bulanan)

\section{Teknik Analisis}

\section{Uji Asumsi Klasik}

\section{Uji Multikolinieritas}

Multikolinieritas adalah hubungan linier yang terjadi diantara variabel independen, meskipun terjadinya multikolinieritas tetap menghasilkan estimator yang BLUE (Best Linier Unbias Estimation). Pengujian terhadap gejala multikoliniearitas dapat dilakukan dengan menggunakan Correlation Matrix dengan jika suatu nilai correlation antar variabel independen lebih kecil dari 0.8 maka, nilai data tersebut dapat dikatakan bebas dari gejala multikolinieritas (Gujarati, 1999)

\section{Uji Autokorelasi}

Uji Autokorelasi bertujuan untuk menguji apakah dalam model regresi linear ada korelasi antara kesalahan pengganggu pada periode $\dagger$ dengan kesalahan pengganggu pada periode t- 1 (sebelumnya).Jika terjadi korelasi maka dinamakan ada problem autokorelasi.Pada penelitian ini menggunakan pengujian Breusch-Godfrey Serial Correlation LM Test dengan membandingkan nilai Obs*Rsquare dengan nilai Chi-Square.Dalam hal iini, hipotesis pendugaan masalah autokorelasi adalah tinggi Obs*R-square dengannilai Chi-Square. (Gujarati, 1999)

\section{Uji Heteroskedastistas}

Heteroskedastistas adalah varian dari residual model regresi yang digunakan dalam penelitian tidak homokedastis atau dengan kata lain tidak konstan. Data yang diambil dari pengamatan satu ke lain atau data yang diambil dari observasi satu ke yang lain tidak memiliki residual yang konstan atau tetap. Untuk menguji ada tidaknya heterosledastistas maka dapat digunakan metode uji White. Uji keberadaan heteroskedastistas dilakukan dengan menguji residual hasil estimasi menggunakan metode White Heteroskedasticity test (No Cross Term) dengan membandingkan nilai Obs*R- 
Hidayat, et al/Jurnal Ekonomi Syariah Teori dan Terapan Vol. 5 No. 4 April 2018: 279-289; KEBIJAKAN FINANCING TO VALUE, FINANCING TO DEPOSIT RATIO DAN PENGARUHNYA TERHADAP PEMBIAYAAN RUMAH DI JAWA TIMUR TAHUN 2013-2015

square dengan nilai Chi-square.(Gujarati,

1999)

\section{Uji Normalitas}

Uji Normalitas adalah untuk mengetahui apakah residual terdistribusi secara normal atau tidak, pengujian normalitas dilakukan menggunakan metode Jarque-Bera. Residual dikatakan memiliki distribusi normal jika Jarque Bera > Chi-square, dan atau probabilitas ( $p$ value) $>a=5 \%$. (Gujarati, 1999)

\section{Uji Hipotesis}

\section{Uji t-statistik}

Uji t-statistik pada dasarnya menunjukkan seberapa jauh pengaruh suatu variabel independen secara individual dalam menerangkan variasi variabel dependen (Ghozali, 2011). Pengujian hipotesis koefisien regresi dengan menggunakan uji $t$ pada tingkat kepercayaan 95 persen dengan derajat kebebasan df = (n-k-1). (Gujarati, 1999)

\section{Uji f-statistik}

Pengujian ini memperlihatkan hubungan atau pengaruh antara variabel independen secara bersama-sama terhadap variabel dependen. Pengujian hipotesis secara keseluruhan dengan menggunakan uji statistic f-hitung dengan menggunakan tingkat kepercayaan 95 persen dengan derajat kebebasan df $1=(k$ 1) dan df2 = (n-k). (Gujarati, 1999)

\section{HASIL DAN PEMBAHASAN}

Berdasarkan hasil penelitian diketahui bahwa Financing to Deposit Ratio berpengaruh secara signifikan positif terhadap pembiayaan rumah di Jawa Timur, hal ini ditunjukan dengan nilai t hitung lebih besar dari t tabel yakni 6,671 > 1,660, selain itu tingkat signifikansinya sebesr 0,00 lebih kecil dari 0,05, sehingga kesimpulannya Financing to Deposit Ratio berpengaruh secara signifikan positif terhadap pembiayaan rumah di Jawa Timur dan $\mathrm{Hl}$ diterima. Nilai positif ini ditunjukan dengan koefisien regresi financing to deposit ratio yang memiliki nilai 0,051, maka dikatakan positif.

Hasil penelitian ini menunjukan bahwa FDR berpengaruh secara signifikan positif didukung oleh penelitian Mariza (2015) menyatakan bahwa, LDR (kebijakan Makroprudensial yang diterapkan oleh perbankan konvensional) berpengaruh secara signifikan terhadap KPR yang terjadi di provinsi Lampung.

Secara teori FDR memang mempengaruhi pembiayaan rumah, dengan semakin banyak pembiayaan yang dikeluarkan oleh perbankan umum syariah maka tingkat FDR akan semakin tinggi, maka dari itu sebaiknya perbankan umum syariah lebih memperhatikan tingkat FDR mereka, karena apabila tingkat FDR mereka makin tinggi maka akan semakin meningkatkan resiko kegagalan perbankan untuk mengembalikan dana pihak ketiga. 
Hidayat, et al/Jurnal Ekonomi Syariah Teori dan Terapan Vol. 5 No. 4 April 2018: 279-289; KEBIJAKAN FINANCING TO VALUE, FINANCING TO DEPOSIT RATIO DAN PENGARUHNYA TERHADAP PEMBIAYAAN RUMAH DI JAWA TIMUR TAHUN 2013-2015

Berdasarkan hasil penelitian ini

diketahui bahwa Financing to Value akad Murabahah-Istishna' berpengaruh secara signifikan negatif terhadap pembiayaan rumah di Jawa Timur. Hal ini ditunjukan dengan nilai t hitung lebih besar dari t tabel yakni $-4,870>1,660$ selain itu, tingkat signifikansinya sebesar 0,00 lebih kecil dari 0,05 .

Kesimpulannya adalah financing to value akad murabahah dan istishna' memiliki pengaruh negatif signifikan terhadap pembiayaan rumah di Jawa Timur dan $\mathrm{Hl}$ diterima.Nilai positif ini ditunjukan dengan koefisiensi regresi financing to value akad murabahah dan istishna' yang memiliki nilai $-0,059$, maka dapat dkatakan negatif.

Hasil penelitian ini didukung oleh Tim Riset SMF (2015) yang menyatakan bahwa pada tahun 2013-2014 terjadi penurunan penyaluran KPR disebabkan oleh kebijakan LTV yang pada saat itu kebijakan LTV sangat ketat yang menganjurkan debitur memberi DP (Down Payment) yang tinggi kepada distributor perumahan.

Berdasarkan hasil penelitian ini diketahui bahwa financing to value akad $M M Q$ dan IMBT memiliki pengaruh positif signifikan terhadap pembiayaan rumah di Jawa Timur, hal ini ditunjukan dengan nilai $\dagger$ hitung lebih besar daripada † tabel yakni $3,780>1,660$ selain itu, tingkat signifikannya sebesar 0,01.
Kesimpulannya FTV akad MMQ dan IMBT memiliki pengaruh positif signifikan terhadap pembiayaan rumah di Jawa Timur dan $\mathrm{HI}$ diterima.Nilai positif ini ditunjukan dengan koefisien regresi FTV akad $M M Q$ dan IMBT yang memiliki nilai 0.414 maka dapat dikatakan positif.

Hal ini dikarenakan rasio total kewajiban debitur untuk membayar Down Payment lebih kecil dari akad murabahah dan istishna', sehingga menyebabkan para debitur akan lebih memilih untuk pembiayaan dengan akad MMQ dan IMBT.

Variabel FDR, FTV akad Murabahah dan Istishna' dan FTV akad MMQ dan IMBT memiliki F-hitung sebesar 49,70 dengan nilai signifikannya 0,00 . F-tabel dengan df penyebut sebesar 30 dan df pembilang 3 , nilai $F$ tabel adalah 2,92. Hasil tersebut menunjukan bahwa $F$ hitung $>F$ tabel $(49,70>2,92)$. Maka dapat disimpulkan bahwa $\mathrm{HO}$ ditolak dan $\mathrm{Hl}$ diterima karena $\mathrm{F}$ hitung lebih besar daripada $\mathrm{F}$ tabel dan nilai tingkat signifikansinya yang melalui $a=5 \%$. Hasil uji F ini menunjukan bahwa FDR, FTV akad Murabahah dan Istishna' dan FTV akad MMQ dan IMBT secara simultan memiliki pengaruh positif signifikan terhadap pembiayaan rumah di Jawa Timur.

\section{Kesimpulan dan Saran}

Berdasarkan hasil perhitungan uji $F$ menunjukan bahwa financing to value lakad murabahah-istishna' ; akad MMQ dan (MBT), financing to deposit ratio berpengaruh secara signifikan terhadap 
Hidayat, et al/Jurnal Ekonomi Syariah Teori dan Terapan Vol. 5 No. 4 April 2018: 279-289; KEBIJAKAN FINANCING TO VALUE, FINANCING TO DEPOSIT RATIO DAN PENGARUHNYA TERHADAP PEMBIAYAAN RUMAH DI JAWA TIMUR TAHUN 2013-2015

pembiayaan rumah di provinsi Jawa Timur periode 2013-2015.

Berdaasarkan perhitungan uji $\dagger$ menunjukan bahwa financing to value akad murabahah-isitshna' berpengaruh signifikan negatif terhadap pembiayaan rumah di provinsi Jawa Timur periode 20132015. Sementara kebijakan financing to value akad $M M Q$ dan IMBT dan financing to deposit ratio berpengaruh secara signifikan positif terhadap pembiayaan rumah di profinsi Jawa Timur periode 2013-2015.

Berdasarkan hasil penelitian terdapat beberapa saran untuk pihak-pihak yang terkait, yaitu Bank Indonesia, Perbankan Umum Syariah dan peneliti selanjutnya yang akan meneliti hal serupa di masa yang akan datang, yaitu:

1. Perbankan Umum Syariah di Jawa Timur harusnya tetap memperhatikan tingkat kesehatan bank terutama tingkat rasio FDR karena itu sangat penting untuk mencegah terjadinya kenaikan tingkat kredit macet yang menyebabkan terjadinya kembali krisis ekonomi yang terjadi pada 2008 ketika sektor riil di Amerika Serikat mengalami collapse dan mengakibatkan krisis ekonomi di Amerika.

2. Bank Indonesia diharapkan meneruskan dan terus membenahi kebijakan FTV dan LTV di Indonesia karena dengan kedua kebijakan ini dapat mengurangi risiko menggelembungnya harga rumah dan properti yang lainnya.

3. Bagi peneliti selanjutnya yang akan mlakukan penelitian dengan subjek yang sama, diharapkan untuk bisa menggunakan kebijakan makroprudensial yang lain yang diterapkan di Indonesia atau denga memperluas subyek penelitian. Mengacu pada hasil penelitian $\mathrm{R}^{2}$ bahwa sekitar $20 \%$ pembiayaan rumah di Jawa Timur didapat dari variabel eksogen maupun endogen lain. Karena kebijakan FTV dan FDR tidak hanya berfokus kepada pembiayaan rumah saja

\section{DAFTAR PUSTAKA}

Agung, Juda. 2010. Mengintegrasikan Kebijakan Moneter dan Makroprudensial: Menuju Paradigma Baru Kebijakan Moneter di Indonesia Pasca Krisis Globa; Working Paper, No. 07. Bank Indonesia

Arnold, Bruce, Claudio Borio, Luci Ellis dan Fariborz Moshiran. 2012. Syatemic Risk, Maroprudential Policy Frameworks, Monitoring Financial System, and the Evolution of Capital Adequacy, Journal of Banking and Finance, vol 36: 3125-3132

Anshori, Muslich \& Sri Iswati. 2009. Metodologi Penelitian Kuantitatif, Surabaya: Airlangga University Press 
Hidayat, et al/Jurnal Ekonomi Syariah Teori dan Terapan Vol. 5 No. 4 April 2018: 279-289; KEBIJAKAN FINANCING TO VALUE, FINANCING TO DEPOSIT RATIO DAN PENGARUHNYA TERHADAP PEMBIAYAAN RUMAH DI JAWA TIMUR TAHUN 2013-2015

Bank of England. 2009. The Role of Macroprudential Policy. A Discussion Lhokseumawe: STAIN Malikussaleh Paper, November

\section{Instrument of Macroprudential Policy. A Discussion Paper, December}

Gujarati, Damodar. 1999. Ekonometrika Dasar, Terjemahan Sumarno Zain, Erlangga, Jakarta

Kasmir. 2003. Bank dan Lembaga Keuangan Lainnya. Jakarta : Raja Grafindo Persada

Mariza, Princes Dianria. 2015. Analisis Pengaruh Kebijakan Loan to Value, Inflasi, Suku Bunga Kredit, dan Loan to Deposit Ratio terhadap Penyaluran Kredit Pemilikan Rumah Provinsi Lampung Periode 2010;012014;09. Lampung : Universitas Lampung

Purnawan, Muhammad Edhie dan M. Abd. Nasir. 2015. The Role of Macroprudential Policy to Manage Exchange Rate Volatility, Excess anking Liquidity and Credits. Jakarta : Bank Indonesia

Quint, Dominic dan Pau Rabanal. 2011. Monetary and Macroprudential Policy in an Estimated DSGE Model of Euro Area. 12 $2^{\text {th }}$ Jacques Polak Annual Research Confrence, November.

Tim Riset SMF, 2015, Dampak Perubahan Loan to ValveTerhadap Perkembangn Kredit Pemiikan Rumah.

Sugiono. 2011. Metode Penelitian Pendekatan Kuantitatif, Kualitatif, dan R\&D. Bandung: ALFABETA

Suryani, 2011, Analisis Pengaruh Financing to Deposit Ratio (FDR) Terhadap Profitabilitas Perbankan Syariah, 